\title{
Feedback to the Future: A Pedagogic Algorithmic Approach to Curating and Delivering Impactful Feedback
}

\author{
Dr. Russell Crawford * \\ Director of Learning and Teaching, Falmouth University \\ Penryn Campus, Treliever Road, Penryn TR10 9FE \\ E-mail: Russell.Crawford@falmouth.ac.uk
}

\section{There are no conflicts of interest}

\begin{abstract}
The Falmouth Formative Feedback $\left(\mathrm{F}^{3}\right)$ Cycle is a Falmouth University created feedback model that has been created using a pedagogic algorithmic approach and is used to aid pedagogic decision making when an individual is planning and then delivering formative feedback, in any context. Our feedback cycle emerged from collecting institutional practice across the 9 diverse industry-linked academic schools at Falmouth and represents a holistic, detailed and directed way to offer feedback to any learner. This is particularly critical as learning and teaching practice changes post-pandemic but there will always remain a vital need for good quality feedback that allows learners to develop under any educational circumstance. What the $\mathrm{F}^{3}$ Cycle therefore provides is a scaffolded and flexible way for learning and teaching practitioners to craft their feedback to the educational, personal, and professional needs of the learner whilst simultaneously encouraging professional development in those providing the feedback through use of different types, structures, and motivations of formative feedback so that positive impacts are the rule, rather than a by-product, of good feedback.
\end{abstract}

Keywords: Feedback, Feed Forward, Pedagogy

DOI: $10.7176 / \mathrm{JEP} / 12-24-05$

Publication date:August $31^{\text {st }} 2021$

\section{Introduction}

The central idea of the $\mathrm{F}^{3}$ Cycle is that feedback should always be forward looking, and this is especially true in the current post-pandemic higher education climate, where routes of feedback delivery and actioning drastically changed in a historically short space of time (Casanova et al, 2021). The jewel in the crown of any learning and teaching practitioner is the success, style, and impact of their feedback on the learner. It is no understatement to suggest that in a learning and teaching context, unless feedback has impact there is functionally no point in giving it in the first place (Jeffery \& Halcomb-Smith (2020).

\section{The Falmouth Formative Feedback $\left(F^{3}\right)$ Cycle}

There is an everlasting driver in the education sector to provide really good quality formative feedback and the only way that will be consistently possible is by empowering the educator, the business partner and indeed, learner peers in selecting the most efficient, appropriate, and impactful ways to refine their feedback (Knight et al, 2020).

Falmouth University`s Learning and Teaching Directorate have created and continue to evaluate the $\mathrm{F}^{3}$ Cycle in response both to the recent pandemic as part of institute-wide at-scale curriculum refresh and specifically in response to National Student Survey (NSS) trends in the wider HE sector around student perceptions of what "good" feedback looks like. The $\mathrm{F}^{3}$ Cycle adopts a pedagogic algorithmic approach to outline a sequential user-focused set of evidence-informed guidance that anyone providing feedback in educational context (from schools to further and higher education) can adopt or adapt to scaffold the implementation of their feedback to ensure positive impacts for the learners (Bearman et al, 2021).

The core pedagogic rationale underpinning the $\mathrm{F}^{3}$ Cycle is one of "Feedback Gain", in essence using the concept of what gains the feedback recipient will get from the feedback so that there is an evaluative "distance travelled" between getting the feedback and then acting on it. Taking this approach means that anyone using the $\mathrm{F}^{3}$ Cycle to tailor their feedback practices, has at their disposal an evidence-informed algorithmic way to ensure that the feedback they are delivering is "impactful" for the person receiving it. The learning and teaching benefits of adhering to this cycle is therefore in consistency but also the layers of thought that go into providing "good feedback". If the learner can action their feedback, then we are significantly along the road of having that desirable "impact" as educators (Dietrich et al, 2020)

The Falmouth Formative Feedback $\left(F^{3}\right)$ Cycle

What the $\mathrm{F}^{3}$ Cycle provides is an algorithmic, scaffolded and flexible way to craft feedback for educational, personal, and professional needs of the recipient whilst simultaneously encouraging considerations of type of feedback (verbal, written, audio or options such as comment-based, goal-referenced and clarification-based 
feedback) structure (informal, coaching, group etc.) and motivation of feedback so that positive impacts are the rule, rather than a by-product of good quality formative feedback. Specifically, the $\mathrm{F}^{3}$ Cycle starts at the 12 $\mathrm{O}$ 'clock position with its first step:

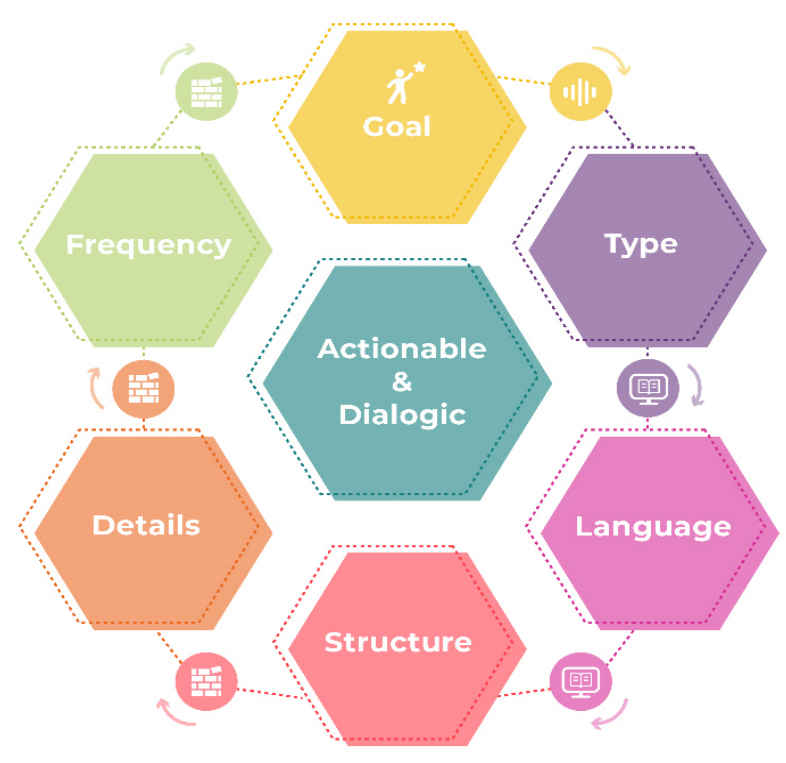

GOAL: The $\mathrm{F}^{3}$ Cycle starts at the GOAL step to begin from a position of encouraging self-regulated learning from students as formative feedback means they can take control of their own learning (Eitel et al, 2020). This first step is therefore about staff providing feedback that a student can then apply to their future learning (and indeed, assessments). The GOAL step is essentially a staff / student conversation before offering specific feedback and focusses on the personal development goals of the student and what they want from the feedback (grades, confidence, experience etc.). This step and pedagogic practice are excellent for encouraging critical thinking and to provide post-assessment value for the student, thereby contributing to satisfaction and student experience (Faridah et al, 2020).

\section{TYPES}

There are myriad types of formative feedback we have at our disposal as educators from a pedagogic standpoint. Some are very specific in nature, and some are very broad in application, so it comes down to our intentions and the disciplinary contexts we offer feedback within, to decide which type works best.

As a working list of popular feedback "types" there are:

\begin{tabular}{|l|l|l|l|l|}
\hline Verbal & Written & Audio & Criticism-based & Discussion-based \\
\hline Comment-based & Advice & Guidance & Direction & Grade-based \\
\hline Negative & Corrective & Goal-referenced & Observational & Review \\
\hline Clarification-based & Intrinsic & Extrinsic & Motivational & Instructional \\
\hline
\end{tabular}

When selecting one or more of these types of feedback to provide, educators must therefore think of the intention (i.e., think on how your feedback could be used to help the recipient improve) and then link that with the next step in the cycle (Zhang, 2021).

\section{LANGUAGE}

Drawing of the pedagogy of Carol Dweck and her "growth mindsets" work, educational practitioners should be paying particular attention to two types of language which can impact on how feedback is received by learners: Person vs. Process Praise (Brummelman and Dweck, 2020).

Briefly, person praise is language that refers to innate or personal aspects within the recipient, for example "You are very clever". Process praise, on the other hand, refers to work, effort, or action rather than the individual, for example "it is clear you worked very hard on this". Whilst both are valid forms of feedback, person praise carries inherent risks to motivation, self-image and confidence if misapplied or misunderstood and, once that individual encounters a problem it can negatively impact on them as "I'm not clever enough", which can be damaging/self-limiting. Where possible the language of the feedback (both verbal and in written forms) should be mindful of these two forms of praise to ensure maximal positive impact of the feedback and how it will be received (Reavis et al, 2018).

\section{STRUCTURE}

There are multiple forms of structure that formative feedback can take and it is critical when deciding on the structure you consider the logistics of the learning environment (for example, is it being given to small or large groups, online or in person) and what the best structure is to apply in tandem with the decisions made from the previous step (for example, observational feedback is easier to provide when using an informal or coaching structure). 
The most common "structures" of formative feedback are:

\begin{tabular}{|l|l|l|l|l|}
\hline Ipsative* & Group & Informal & Formal & Constructive \\
\hline Peer & Critique & Feed-forward & Delayed & Appreciation \\
\hline Evaluation & Coaching & & & \\
\hline
\end{tabular}

*learners are informed about their progress and development, comparing to the previous task presented and providing strategies to identify major issues to be overcome for the next task.

Deciding on the most suitable structure for the feedback is therefore critical in ensuring it is received to maximal positive impact, as it very much plays a role in the "how" of the delivery of the feedback that can either enhance or detract from it (Gardiner, 2017).

\section{DETAILS}

The pedagogic benchmark in use when thinking about the level of detail feedback should have to make it effective is to follow the axiom of all formative feedback should be able to be acted upon to allow improvement. When a feedback provider thinks "details", they should therefore be asking if the feedback is:

\begin{tabular}{|l|l|l|l|l|}
\hline Specific & Appropriate & Credible & Possible to use/do & $\begin{array}{l}\text { proactive (looking } \\
\text { for trends) }\end{array}$ \\
\hline Descriptive enough & Non-judgmental & Clear & $\begin{array}{l}\text { Culturally relevant } \\
\text { (educational) }\end{array}$ & $\begin{array}{l}\text { Based on data and } \\
\text { /or behaviour }\end{array}$ \\
\hline Timely & Iterative & Contextual & & \\
\hline
\end{tabular}

In that regard, a better pedagogic concept to use when thinking about the detail of feedback is that of Feed Forward, which spends less time looking at the past (i.e., "what I did wrong") and much more time as part of the $\mathrm{F}^{3}$ Cycle asking, "what I need to do to improve in the future" (Vattøy, and Smith, 2019). A hallmark of a feed forward approach is that rather than offering feedback on a completed piece of work, we offer guidance for improving that work iteratively over a discrete period, in essence encouraging incremental improvement though reflection on the feedback, which leads to the final step in the $\mathrm{F}^{3}$ Cycle.

\section{FREQUENCY}

This aspect of the $\mathrm{F}^{3}$ Cycle is highly personal to the educational context the feedback will be offer within and indeed, constitutes as many logistical as educational decision-making factors, from workload to group size, from timing to accessibility for the recipients ( $\mathrm{Wu}$ and Schunn, 2020). This step in the $\mathrm{F}^{3}$ Cycle is to allow those giving feedback to consideration the needs of their learners and to inform decisions on just how often and in what format their feedback is provided (especially if using a feed forward approach). This is critical to allow both the feedback giver and receiver to each have sufficient reflection and improvement time to ensure the feedback is actionable and impactful. In this way, the final step of the $\mathrm{F}^{3}$ Cycle step ensures continuing communication between educational practitioner and recipient, essentially delivering "Feedback Gain" through developmental conversation (and nicely mirrors the first step in the $\mathrm{F}^{3}$ Cycle, taking us full circle back to the dialogic aspects of feedback).

\section{Future Directions}

Where the $\mathrm{F}^{3}$ Cycle might come into its own in the future is when taking the above ideas and applying them outside the University environment and into the business, self-employment, and post-education world (beyond the scope of the current paper but a focus of our ongoing work). For example, in an industrial context, our feedback cycle could be used to scaffold professional development as well as form part of formal performance review. In a further education context, our cycle could form part of a peer-review and feedback component of formative course work development and in a self-employment context, the feedback cycle could be used to structure customer feedback to allow businesses to improve in meaningful ways. Thus, application of the $\mathrm{F}^{3}$ Cycle can be diverse as, having an appreciation of and ability to deliver impactful feedback is a key survival skill in the "real" world and future work will determine to what degree this is the case (Peschl et al, 2021). Our future evaluation work will next focus on large scale and longitudinal evaluation of the impacts that use of the cycle can have on student confidence and learning gain.

\section{In Summary}

What the $\mathrm{F}^{3}$ Cycle therefore provides is a scaffolded and flexible way for educational practitioners to craft their feedback to the educational, personal, and professional needs of the learner whilst simultaneously encouraging consideration (and therefore improving continued professional development) of different types, structures and motivations of formative feedback so that positive impacts are the rule determining what "good" feedback looks like from the learner's perspective. 


\section{References (in order of citation):}

Casanova D, Alsop G, Huet I. Giving away some of their powers! Towards learner agency in digital assessment and feedback. Research and Practice in Technology Enhanced Learning. 2021 Dec;16(1):1-9.

Jeffery, K. and Halcomb-Smith, L., 2020. Innovation, Critical Pedagogy, and Appreciative Feedback: A Model for Practitioners. In Enhancing Learning Design for Innovative Teaching in Higher Education (pp. 1-21). IGI Global.

Knight, S., Shibani, A., Abel, S., Gibson, A., Ryan, P., Sutton, N., Wight, R., Lucas, C., Sandor, A., Kitto, K. and Liu, M., 2020. AcaWriter: A learning analytics tool for formative feedback on academic writing. Journal of Writing Research, 12(1), pp.141-186.

Bearman, M., Brown, J., Kirby, C. and Ajjawi, R., 2021. Feedback that helps trainees learn to practice without supervision. Academic Medicine, 96(2), pp.205-209.

Dietrich, S.W., Goelman, D., Broatch, J., Crook, S.M., Ball, B., Kobojek, K. and Ortiz, J., 2020. Using formative assessment for improving pedagogy: reflections on feedback informing database visualizations. $A C M$ Inroads, 11(4), pp.27-34.

Eitel, A., Endres, T. and Renkl, A., 2020. Self-management as a bridge between cognitive load and selfregulated learning: The illustrative case of seductive details. Educational Psychology Review, pp.1-15.

Faridah, D., Thoyyibah, L. and Kurnia, A.D., 2020. PROMOTING STUDENTS CRITICAL THINKING THROUGH PEER FEEDBACK IN ORAL COMMUNICATION CLASSROOM. Academic Journal Perspective: Education, Language, and Literature, 8(1), pp.50-59.

Zhang, Z., 2021. Promoting student engagement with feedback: insights from collaborative pedagogy and teacher feedback. Assessment \& Evaluation in Higher Education, pp.1-16.

Brummelman, E. and Dweck, C.S., 2020. Paradoxical effects of praise: A transactional model. In Psychological Perspectives on Praise (pp. 55-64). Routledge.

Reavis, R.D., Miller, S.E., Grimes, J.A. and Fomukong, A.N.N., 2018. Effort as person-focused praise:"Hard worker" has negative effects for adults after a failure. The Journal of genetic psychology, 179(3), pp.117122.

Gardiner, P., 2017. Rethinking feedback: Playwriting pedagogy as teaching and learning for creativity. Teaching and Teacher Education, 65, pp.117-126.

Vattøy, K.D. and Smith, K., 2019. Students' perceptions of teachers' feedback practice in teaching English as a foreign language. Teaching and Teacher Education, 85, pp.260-268.

$\mathrm{Wu}, \mathrm{Y}$. and Schunn, C.D., 2020. When peers agree, do students listen? The central role of feedback quality and feedback frequency in determining uptake of feedback. Contemporary Educational Psychology, 62, p.101897.

Peschl, H., Deng, C. and Larson, N., 2021. Entrepreneurial thinking: A signature pedagogy for an uncertain 21st century. The International Journal of Management Education, 19(1), p.100427. 